\title{
Gravity wave influence on NLC: experimental results from ALOMAR, $69^{\circ} \mathrm{N}$
}

\author{
H. Wilms ${ }^{1}$, M. Rapp ${ }^{1,2}$, P. Hoffmann ${ }^{3}$, J. Fiedler ${ }^{3}$, and G. Baumgarten ${ }^{3}$ \\ ${ }^{1}$ Deutsches Zentrum für Luft- und Raumfahrt, Institut für Physik der Atmosphäre, Oberpfaffenhofen, Germany \\ ${ }^{2}$ Meteorologisches Institut München, Ludwig-Maximilians-Universität München, Munich, Germany \\ ${ }^{3}$ Leibniz Institute of Atmospheric Physics, Schlossstr. 6, 18225 Kühlungsborn, Germany
}

Correspondence to: H. Wilms (henrike.wilms@dlr.de)

Received: 6 June 2013 - Published in Atmos. Chem. Phys. Discuss.: 31 July 2013

Revised: 7 November 2013 - Accepted: 9 November 2013 - Published: 10 December 2013

\begin{abstract}
The influence of gravity waves on noctilucent clouds (NLC) at ALOMAR $\left(69^{\circ} \mathrm{N}\right)$ is analysed by relating gravity wave activity to NLC occurrence from commonvolume measurements. Gravity wave kinetic energies are derived from MF-radar wind data and filtered into different period ranges by wavelet transformation. From the dataset covering the years 1999-2011, a direct correlation between gravity wave kinetic energy and NLC occurrence is not found, i.e., NLC appear independently of the simultaneously measured gravity wave kinetic energy. In addition, gravity wave activity is divided into weak and strong activity as compared to a $13 \mathrm{yr}$ mean. The NLC occurrence rates during strong and weak activity are calculated separately for a given wave period and compared to each other. Again, for the full dataset no dependence of NLC occurrence on relative gravity wave activity is found. However, concentrating on $12 \mathrm{~h}$ of NLC detections during 2008, we do find an NLC-amplification with strong long-period gravity wave occurrence. Our analysis hence confirms previous findings that in general NLC at ALOMAR are not predominantly driven by gravity waves while exceptions to this rule are at least possible.
\end{abstract}

\section{Introduction}

Noctilucent clouds (NLC), also named polar mesospheric clouds (PMC) when observed from space, are a remarkable feature of the polar summer mesopause. These clouds, first documented by Leslie (1885), Jesse (1885) and Backhouse (1885), are the direct indication of extremely low temperatures enabling ice particle growth to visible sizes. Owing to the high altitude of about $83 \mathrm{~km}$ NLC can be observed by the naked eye when the sun is $6^{\circ}$ to $15^{\circ}$ below the horizon and illuminates the thin clouds from below (Gadsden and Schröder, 1989).

NLC are subject to a high degree of variability on scales ranging from minutes to decades. Long-term trends have been identified in the brightness of polar mesospheric clouds (DeLand et al., 2007) as well as their occurrence frequency (Shettle et al., 2009). According to model results these trends are mainly due to temperature changes of the mesopause, induced by the shrinking of the stratosphere, and solar cycle modulations of mesospheric water vapour content (Lübken et al., 2009; Lübken and Berger, 2011). The temperature in the mesopause region features a strong seasonal cycle, which provides sufficiently low temperatures for ice formation only during the summer months. Thus, the dynamically driven cooling of the mesopause (e.g., Holton, 1982) determines the onset of the NLC season around 20 days prior to solstice (DeLand et al., 2006). On the shorter end of scales, namely minutes to days, NLC are highly influenced by dynamical features of the mesopause. For example, diurnal and semi-diurnal variations of NLC occurrence frequency, brightness and central height due to tides have been detected in lidar measurements at several sites, including the South Pole (Chu et al., 2001), Rothera, Antarctica (Chu et al., 2006) and ALOMAR, Norway (von Zahn et al., 1998; Fiedler et al., 2005, 2011). The signature of planetary waves in PMC occurrence and brightness has been detected in satellite measurements (e.g., Merkel et al., 2008, 2009) and also in images taken with a ground based camera network (Dalin et al., 2008). Gravity waves can induce temperature fluctuations 
as high as $10 \mathrm{~K}$ (e.g., Rapp et al., 2002), which influence in a complex interplay with vertical winds and sedimentation the growth of ice particles. The signatures of wavelike structures in NLC have been used to determine gravity wave parameters from ground-based (e.g., Witt, 1962; Pautet et al., 2011) and satellite-based (e.g., Chandran et al., 2009) images and recently also from high resolution lidar data (Kaifler et al., 2013). NLC therefore open a possibility to study small scale dynamics in the mesopause which are not accessible by other remote-sensing methods. However, for the correct interpretation of NLC variability in terms of gravity wave activity, it is of crucial importance to clearly understand all processes modifying NLC parameters.

Model simulations of NLC under the influence of gravity waves have shown that short period gravity waves tend to destroy NLC, whereas longer period gravity waves enhance NLC (Turco et al., 1982; Jensen and Thomas, 1994; Rapp et al., 2002; Chandran et al., 2012), with the transition period lying at $6.5 \mathrm{~h}$ (Rapp et al., 2002). This anticorrelation for short period gravity waves has been confirmed by lidar measurements at the South Pole (Chu et al., 2009) and in Sondrestrom, Greenland (Thayer et al., 2003; Gerrard et al., 2004). On the contrary, no such anticorrelation was found in Rothera, Antarctica (Chu et al., 2009), Davis, Antarctica (Innis et al., 2008) and ALOMAR, Norway (Schöch, 2007). The applied methodology was basically the same at all locations: density fluctuations in the stratosphere serve as a measure for gravity wave activity, which is then correlated to mesospheric cloud parameters. The underlying assumption thereby is that gravity waves in the stratosphere are closely related to those in the mesosphere. Consequently, modifications of the gravity wave spectrum due to filtering processes by the background wind (Eckermann, 1995) are not taken into account, as well as non-vertically propagating gravity waves (Ern et al., 2011; Preusse et al., 2009; Sato et al., 2009). Altogether it is not known, how and to what extent the gravity wave field changes during $40 \mathrm{~km}$ of upward propagation. So far, it has not been identified, whether the absence of an anticorrelation between gravity wave activity and NLC brightness at Rothera, Davis and ALOMAR can be attributed to probing different volumes for gravity waves and NLC, or whether gravity waves are indeed only a minor contributor to NLC brightness at those sites.

The aim of this work is to closer examine this question by determining gravity wave parameters in a common volume with NLC observations. We combine lidar measurements from ALOMAR, the arctic atmospheric research site in Andenes, Norway, with mesospheric wind measurements by a closely located radar. The data used for the following analysis is briefly described in Sect. 2. Gravity wave activity in different period ranges is determined by filtering of the wind data by means of a wavelet transformation, which is explained in Sect. 3. The results of two different methods analysing the relation of NLC and gravity wave occurrence are presented in Sect. 4 and discussed in Sect. 5. The concluding Sect. 6 summarises our results.

\section{Data base}

For the following analysis of the correlation between NLC occurrence rates and the presence of gravity waves, datasets obtained by lidar and radar in Andenes, Northern Norway $\left(69.3^{\circ} \mathrm{N}, 16.0^{\circ} \mathrm{E}\right)$ are combined.

Wind data used for determining gravity wave activity was obtained with the Andenes MF radar which operates at $1.98 \mathrm{MHz}$ and continuously provides wind measurements between $70 \mathrm{~km}$ and $94 \mathrm{~km}$. A vertically directed wide beam antenna transmits electromagnetic pulses of $4 \mathrm{~km}$ length with a peak power of $50 \mathrm{~kW}$. Three crossed dipoles arranged in an equilateral triangle collect the atmospheric return signal (see Singer et al., 1997 for details). For determining the horizontal wind speed the spaced-antenna method (Briggs, 1984) is applied to the return signal and the height bins are oversampled to yield a height resolution of $2 \mathrm{~km}$. The data is collected with a time resolution of $3 \mathrm{~min}$ and is then averaged over $1 \mathrm{~h}$ for the following analysis. The uncertainty of the wind velocities is $2 \mathrm{~ms}^{-1}$ (Gonzalez et al., 1994). Gravity wave activity in different period bands is derived by means of a wavelet transformation, as previously applied by Hoffmann et al. (2010).

The Rayleigh/Mie/Raman- (RMR-) lidar at the Arctic Lidar Observatory for Middle Atmosphere Research (ALOMAR) is optimized for the detection of NLC by using a spectral highly stable laser and strong spatial and spectral filtering in the detection unit (von Zahn et al., 2000). This allows lidar measurements throughout the Arctic summer at all local times. Lidar count rate profiles are converted to volume backscatter coefficients $\beta(z)$ depending on the altitude $z$ and NLC are identified where $\beta(z)$ is greater than the measurement uncertainty $\Delta \beta(z)$. Details about the data processing are described by Fiedler et al. (2009). For our analysis the maximum backscatter coefficient $\beta_{\max }$ and the centroid altitude $z_{\mathrm{c}}$ were extracted from $14 \mathrm{~min}$ averaged profiles. In the year 2006, a major improvement of the detection limit was achieved which reduced the uncertainty to $\Delta \beta \approx 1 \times$ $10^{-10} \mathrm{~m}^{-1} \mathrm{sr}^{-1}$ from previously $\Delta \beta \approx 4 \times 10^{-10} \mathrm{~m}^{-1} \mathrm{sr}^{-1}$ (Fiedler et al., 2011), thus allowing the detection of weaker NLC. To ensure that the analysis is performed on the same brightness classes of NLC in every year and that the analysis is unaffected by the change of the detection threshold, we will consider the NLC data in the long-term detection limit (Fiedler et al., 2009) which only includes backscatter coefficients with $\beta_{\max }>4 \times 10^{-10} \mathrm{~m}^{-1} \mathrm{sr}^{-1}$. The use of the highsensitivity data $\left(\beta_{\max }>1 \times 10^{-10} \mathrm{~m}^{-1} \mathrm{sr}^{-1}\right)$ will be stated explicitly. 


\section{Data processing}

\subsection{Wavelet analysis}

As model simulations predict that the impact of gravity waves on mesospheric ice layers depends on the waves' period (Turco et al., 1982; Jensen and Thomas, 1994; Rapp et al., 2002; Chandran et al., 2012), we performed our analysis period-dependently. A suitable tool to extract the time evolution of different period components of a signal is the wavelet transformation. Based on the description of Torrence and Compo (1998), the wavelet transformation $W(s, \tau)$ of the wind time series at a certain scale $s$ and time step $\tau$ have been calculated. As mother wavelet functions the socalled Morlet wavelet, a cosine function with the frequency $\omega_{0}$ as free parameter and damped with a Gaussian window (e.g., Torrence and Compo, 1998), has been employed as well as the Paul-Wavelet (Farge, 1992) of order 4. Following the advice of Liu et al. (2007), each wavelet coefficient is weighted by the square root of its corresponding scale $\tilde{f}(s, \tau)=\frac{W(s, \tau)}{\sqrt{s}}$. This allows the direct comparison of different peaks in the wavelet spectrum in the sense that equal amplitudes in a superposition of harmonic functions lead to equally strong peaks in the spectrum. The local wavelet spectrum or wavelet power is given by $|\tilde{f}(s, \tau)|^{2}$. The sum of the wavelet power over a range of scales, henceforth referred to as a band, results in a time series of the variance in this band (see Eq. 24 of Torrence and Compo, 1998). In this manner we calculate the wind variance in a certain band centred around the mean scale $S$ by using the following relation

$x^{\prime 2}(S, \tau)=\frac{\delta j \delta t}{C_{\delta}} \sum_{j=j_{1}}^{j_{2}}\left|\tilde{f}\left(s_{j}, \tau\right)\right|^{2}$

where $s_{j_{1}}$ and $s_{j_{2}}$ denote the scales equivalent to the lower and upper period of the considered band. The time and scale resolution is given by $\delta t$ and $\delta j$, whereas $C_{\delta}$ is the reconstruction factor depending on the wavelet function. From the variances of the $u$ and $v$ component of the wind the kinetic energy density in the chosen band is calculated as $E_{\text {kin }}(S, \tau)=\frac{1}{2}\left(u^{\prime 2}(S, \tau)+v^{\prime 2}(S, \tau)\right)$ and averaged over the altitude range of $80 \mathrm{~km}$ to $88 \mathrm{~km}$. The band width was chosen to be $2 \mathrm{~h}$, which is a compromise between performing the analysis for different periods and taking the width of a peak produced by a single frequency signal into account. The bands can be chosen around any desired central scale $S$. We use partly overlapping bands with $1 \mathrm{~h}$ spacing between the central periods as indicated in Fig. 1.

\subsection{Normalization of gravity wave kinetic energy}

In the second part of our analysis we will divide the gravity wave activity into strong and weak events. The threshold dividing the two domains is derived for each band and altitude bin from the global wavelet spectrum (the time averaged wavelet power). By analogy with the summation of different scales to calculate the variance in a band (Eq. 1), the same scales of the global wavelet spectrum are summed to calculate the reference variance

$x_{\mathrm{ref}}^{\prime 2}(S)=\frac{\delta j \delta t}{C_{\delta}} \sum_{j=j_{1}}^{j_{2}}\left|\tilde{\mathrm{gl}}_{\mathrm{gl}}\left(s_{j}\right)\right|^{2}$

with the global wavelet spectrum $\tilde{f}_{\mathrm{gl}}(s)=\frac{1}{N} \sum_{\tau=1}^{N} \tilde{f}(s, \tau)$. The global wavelet spectrum is based on the time series from 1 June to 15 August, which covers most of the NLC season at ALOMAR. To ensure comparability between different years, the averaged global wavelet spectrum from the years 1999 to 2011 is used as reference. Normalized wind variances are then obtained by dividing the wind variances by their corresponding reference variance $x_{\text {norm }}^{\prime 2}(S, \tau)=x^{\prime 2}(S, \tau) / x_{\text {ref }}^{\prime 2}(S)$ and accordingly, the normalized kinetic energy is calculated as $E_{\text {kin, norm }}(S, \tau)=\frac{1}{2}\left(u_{\text {norm }}^{\prime 2}(S, \tau)+v_{\text {norm }}^{\prime 2}(S, \tau)\right)$. This procedure is repeated for all height bins and the normalized energies are averaged over the altitude range of $80 \mathrm{~km}$ to $88 \mathrm{~km}$. Enhanced gravity wave activity will be indicated by $E_{\text {kin,norm }}>1$, whereas $E_{\text {kin,norm }}<1$ will denote reduced gravity wave activity. Figure 1 shows in the top panel the global wavelet spectrum used to calculate the reference variance displayed in the bottom panel for the $u$ wind component. Note that the $x$ axis is logarithmic in panel a (as opposed to the linear axis in panel b) because the scales $s$ are fractional powers of 2 (Torrence and Compo, 1998). The global wavelet spectrum exhibits a $f^{-5 / 3}$ frequency dependency (not shown) and the dominant peaks belong to the diurnal and semidiurnal tide at $24 \mathrm{~h}$ and $12 \mathrm{~h}$ respectively. In the gravity wave period range, which comprises periods up to $13 \mathrm{~h}$ corresponding to the Coriolis parameter at ALOMAR, the power spectral density (PSD) of the global wavelet spectrum and also the reference variances increase with increasing altitude as expected from energy conservation. By using the reference variance as normalization factor this amplitude growth is eliminated and the different altitude bins are comparable. The mean value of the different altitude bins will therefore be equally weighted and not biased by the larger variances at higher altitudes.

The reference variances in the $12 \mathrm{~h}$ band is dominated by the variance caused by the semidiurnal tide. The same applies possibly for the terdiurnal tide influencing the $8 \mathrm{~h}$ band. To estimate the bias caused by tides, the main analysis is additionally performed on a dataset where the tides have been removed. The criterion to distinguish gravity waves from tides is that we assume tides, in contrast to gravity waves, to be phase stable for several days. For a time interval of 7 days, the mean wind is subtracted from the wind data and the amplitudes of the tides are derived from a harmonic fit with periods of $8 \mathrm{~h}, 12 \mathrm{~h}$ and $24 \mathrm{~h}$. The time interval is then shifted by 1 day and the fitting procedure is repeated. The tidal components of the wind are then subtracted from the central day of the corresponding time interval. 


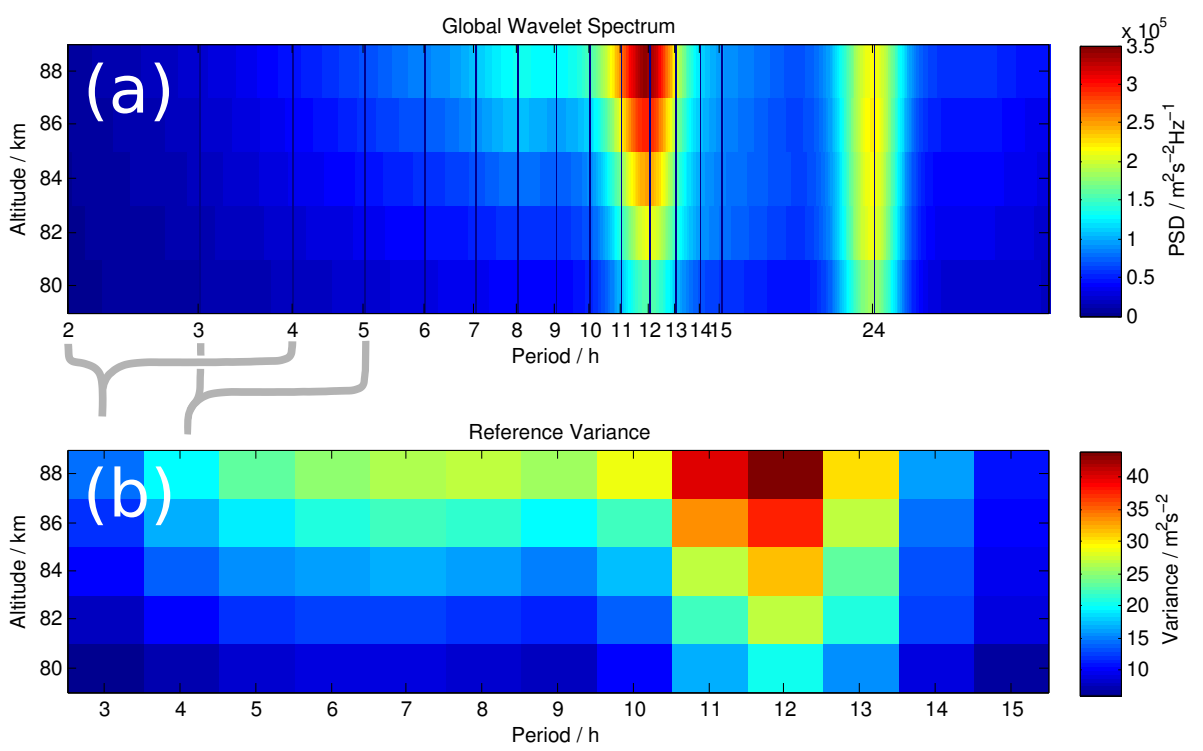

Fig. 1. (a) Global wavelet spectrum based on wind $u$ data from 1 June to 15 August of the years 1999 to 2011. (b) Reference variances obtained from the global wavelet spectrum by summation of overlapping period bands of $2 \mathrm{~h}$ width (see brackets below upper panel).
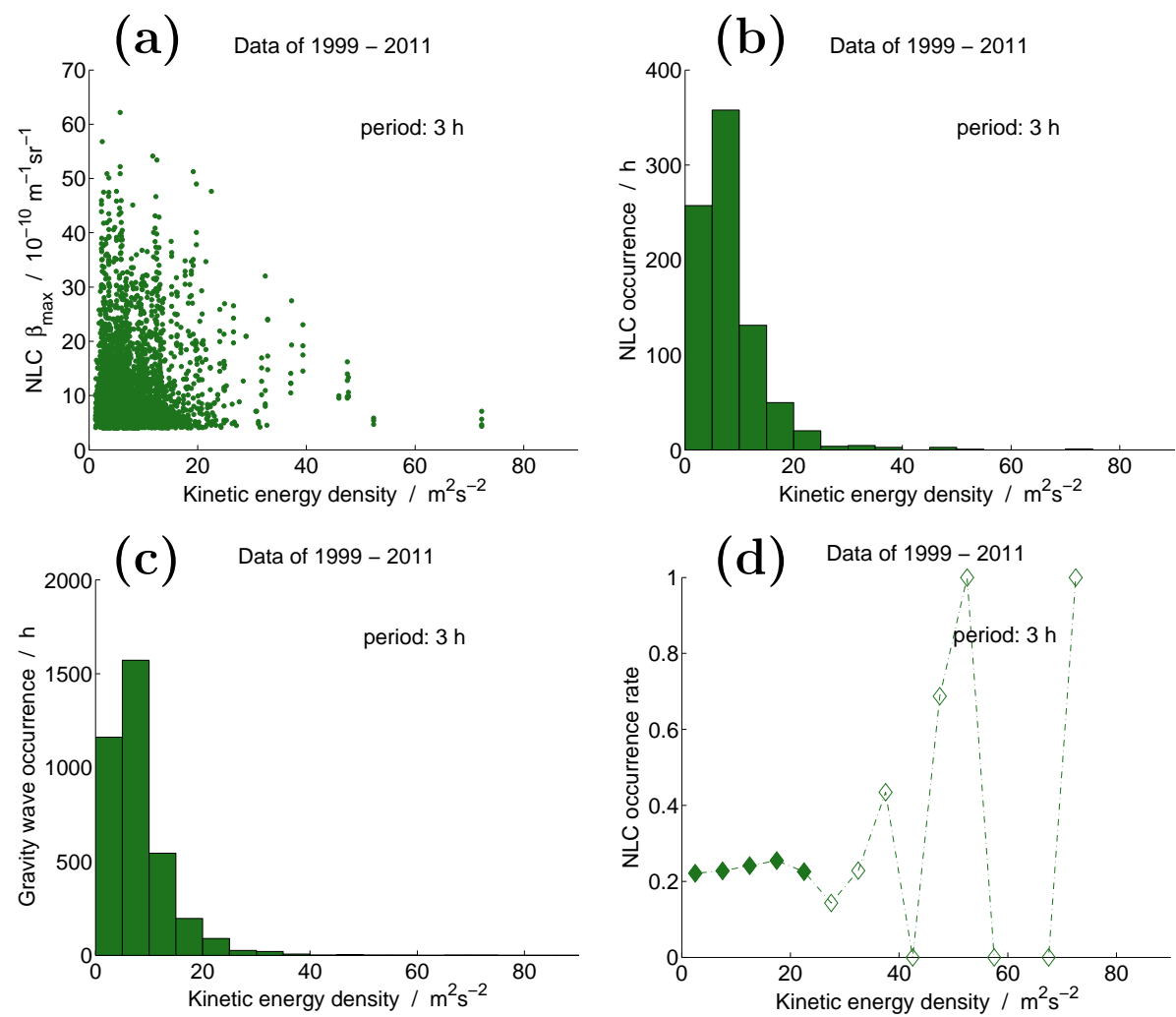

Fig. 2. (a) NLC backscatter coefficient $\beta_{\max }$ vs. gravity wave kinetic energy density in the $2 \mathrm{~h}$ to $4 \mathrm{~h}$ period band. (b) Total time of NLC detection during simultaneously identified gravity wave activity of the $3 \mathrm{~h}$ wave in different energy bins (histogram of a). (c) Total time of gravity wave occurrence of the $3 \mathrm{~h}$ wave in different energy bins during the complete lidar measurement time independent of NLC detection. (d) NLC occurrence rate (ratio of NLC detection time to total measurement time) in different energy bins. Open symbols indicate occurrence rates based on less than $5 \mathrm{~h}$ of NLC detection. 

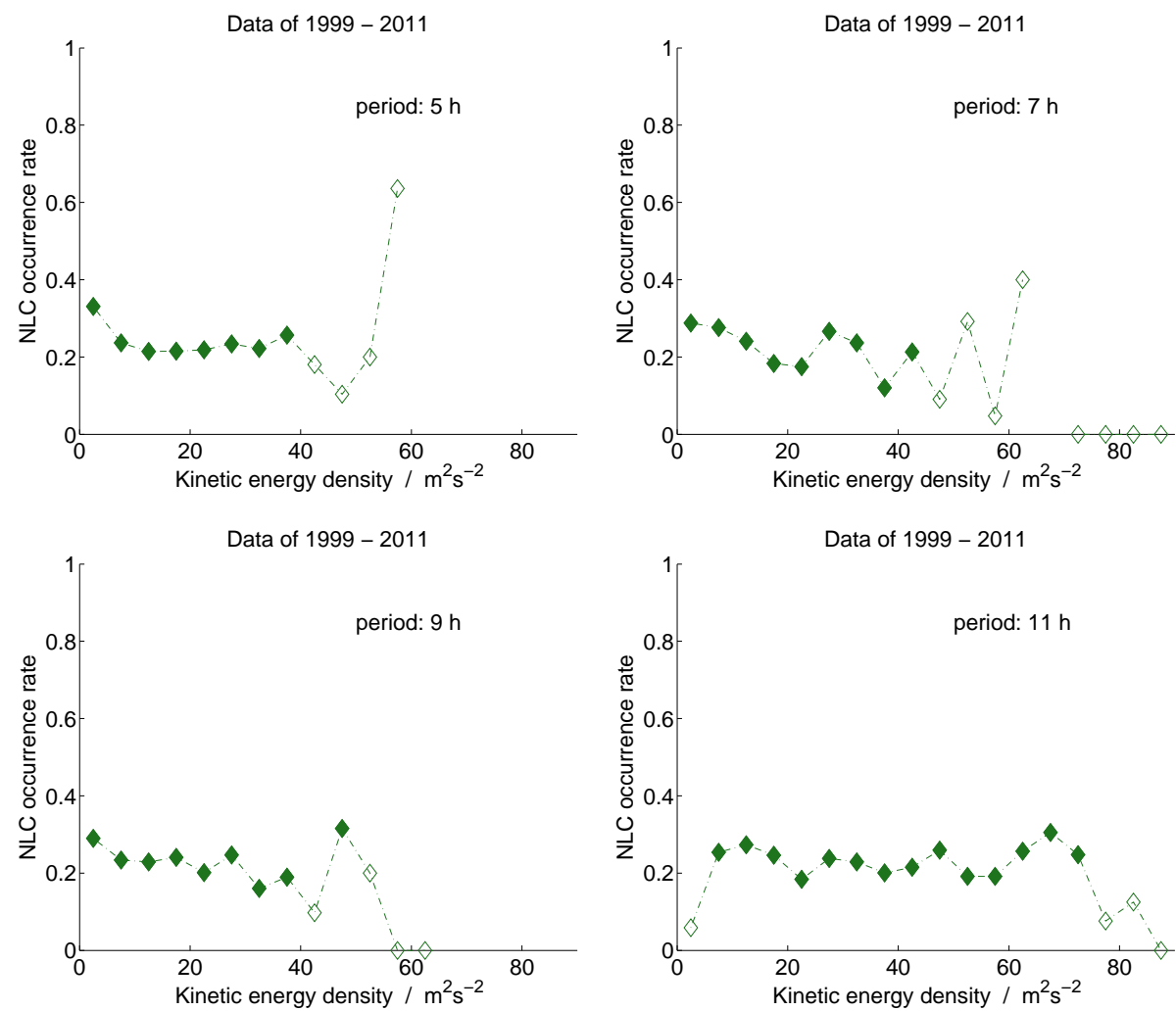

Fig. 3. The same as Fig. 2d, but for the $5 \mathrm{~h}, 7 \mathrm{~h}, 9 \mathrm{~h}$ and $11 \mathrm{~h}$ wave.

\section{Results}

\subsection{Relation of NLC and gravity wave strength}

A direct comparison of NLC backscatter coefficients with the simultaneously occurring gravity wave kinetic energy is shown in Fig. 2a for the complete dataset of 1999-2011 and the $3 \mathrm{~h}$ wave (meaning the kinetic energy in the $2 \mathrm{~h}$ to $4 \mathrm{~h}$ band). The strongest NLC occurred during times of lower gravity wave kinetic energy, whereas mostly weak NLC occurred during times of higher kinetic energy. Most NLC detections coincide with low gravity wave kinetic energy, as indicated by panel $b$, which shows the histogram of NLC detections in different energy ranges. Figure $2 \mathrm{c}$ shows the histogram of gravity wave energies independent of NLC detection during the complete time of lidar measurements. While this figure includes all data points from simultaneous lidar and gravity wave measurements, the data of panel $b$ is limited to those data points of NLC detection and is consequently a subset of the complete dataset of panel c. From the two histograms in panel $\mathrm{b}$ and $\mathrm{c}$ the NLC occurrence rate in different energy ranges is calculated and displayed in panel $\mathrm{d}$. The occurrence rate is defined as the ratio of NLC detection time (panel b) to the total measurement time (panel c), in this specific case limited to certain energy bins of the $3 \mathrm{~h}$ wave. In the higher energy range the NLC occurrence rates are based on datasets containing a factor of 100 less data points than in the maximum, so that single data points have a much greater influence. Occurrence rates based on comparatively small datasets of less than $5 \mathrm{~h}$ (20 data points) of NLC detection are indicated by empty symbols in Fig. 2d. This indicates their high unreliability compared to the occurrence rates at the maximum and these data points will not be considered further.

In this manner the datasets of waves with larger periods ( $4 \mathrm{~h}$ to $12 \mathrm{~h}$ ) were analysed. As the results strongly resemble each other, the NLC occurrence rates of the $5 \mathrm{~h}, 7 \mathrm{~h}, 9 \mathrm{~h}$ and $11 \mathrm{~h}$ wave are presented exemplarily in Fig. 3.

The NLC occurrence rates are uniformly distributed over the different energy bins and show no preference to either higher or lower gravity wave activity. As the wave bands have a width of $2 \mathrm{~h}$, the results for the $11 \mathrm{~h}$ wave are potentially biased by the semidiurnal tide. The results for the $7 \mathrm{~h}$ and $9 \mathrm{~h}$ wave can similarly be influenced by the terdiurnal tide, although the amplitude of the terdiurnal tide is much weaker (compare to Fig. 1) and should have a smaller influence. However, the results for the other periods not shown in Fig. 3 do not feature a different behaviour. We therefore conclude that at ALOMAR there is no explicit dependence of NLC occurrence on gravity wave kinetic energy. 


\subsection{NLC occurrence rates during strong and weak gravity wave activity}

We further developed a second method to analyse the relation of NLC occurrence and gravity wave activity, where we do not focus on the absolute gravity wave energy during NLC events as in the previous method, but classify the gravity wave activity into weak and strong events, relative to a 13 yr summer season mean condition, i.e., from 1 June to 15 August. By this classification, the dataset can be divided into two subsets, one containing all times with enhanced gravity wave strength (indicated by $E_{\text {kin,norm }}>1$ ) and the other containing all times of attenuated gravity wave strength $\left(E_{\text {kin,norm }}<1\right)$. For each subset, the NLC occurrence rate $(\mathrm{OR})$ is calculated and compared with the other. A simple way to compare the two occurrence rates is to consider the ratio

$\eta=\frac{\mathrm{OR}_{\mathrm{NLC}}\left(E_{\mathrm{kin}, \text { norm }}>1\right)}{\mathrm{OR}_{\mathrm{NLC}}\left(E_{\mathrm{kin}, \text { norm }}<1\right)}$.

Figure 4 schematically visualizes the calculation of $\eta$. The rectangle depicts all points in time where wind measurements are available, respectively the oval all points in time where lidar measurements were performed. In our analysis we include all points in the overlapping area (not to size). The data points are then further sorted according to the normalized kinetic energy (upper and lower part of the rectangle) and according to whether NLC were detected or not (right and left part of oval). The NLC occurrence rate at enhanced gravity wave activity is then the fraction of the orange shaded area to the total orange framed area, or in terms of measurement time $\frac{T_{\mathrm{NLC}}}{T_{\mathrm{NLC}}+T_{\mathrm{nNLC}}}$ given $E_{\text {kin, norm }}>1$. For low gravity wave activity, the NLC occurrence rate is calculated correspondingly and $\eta$ is the ratio of both occurrence rates according to Eq. (3). The ratio $\eta$ indicates how much more frequently NLC occurred during strong gravity wave activity than during low activity. A ratio of $\eta=1$ means that NLC occur equally frequently during strong and weak wave activity and that gravity waves do not have a predominant influence on NLC occurrence.

If there was a clear relation between NLC occurrence and gravity waves, such as the model prediction of NLC weakening due to short period gravity waves, we would expect this to be reflected by $\eta$ in the following manner: in the short period range NLC should occur less frequently during strong gravity wave activity, resulting in $\eta<1$. In the long period range gravity waves are expected to enhance NLC, such that NLC should occur more frequently during strong gravity wave activity, resulting in $\eta>1$. Thus, analysing $\eta$ and its period dependency will reveal whether NLC occurred primarily during weak or strong gravity wave activity in the different period ranges.

Figure 5 presents $\eta$ exemplarily for the years 2007, 2008, 2009 and 2011 in the period range from $3 \mathrm{~h}$ to $12 \mathrm{~h}$. These years were selected due to their comparable properties of

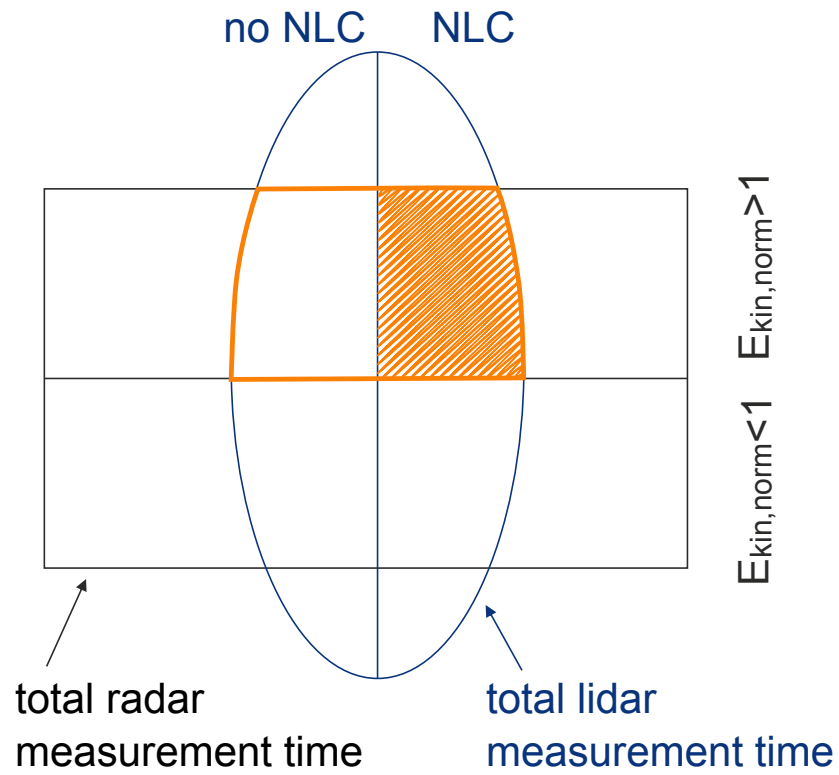

Fig. 4. Schematic visualization of the available lidar and radar data. From the radar data times of high and low gravity wave activity in a certain period range are identified $\left(E_{\text {kin,norm }}>1\right.$ and $E_{\text {kin,norm }}<1$ respectively) and from the lidar data times of NLC detection. The NLC occurrence rate during high gravity wave activity is the fraction of the orange shaded area with respect to the orange framed area.

the underlying NLC dataset with respect to total measurement time and the overall NLC occurrence rate. The ratio $\eta$ shows different trends in the four selected years, especially in 2008 with a pronounced increase of $\eta$ with increasing period. To test whether this trend persists when varying certain parameters, we performed the analysis with three different types of mother wavelet functions. The choice of the mother wavelet has the greatest influence on the calculation of the kinetic energy because it determines the scale resolution of the detected waves, which is inversely related to the time resolution. Therefore, the choice of the mother wavelet highly influences the classification into strong and weak activity of every single data point and consequently also the NLC occurrence rates. The finest scale resolution of our three types is obtained by the Morlet wavelet with parameter $\omega_{0}=10$, the finest time resolution by the Paul wavelet of order 4. An additional uncertainty of $\eta$ is constituted by the uncertainty of the raw wind data of about $2 \mathrm{~ms}^{-1}$. To estimate the sensitivity of $\eta$ to errors of the wind data, we added random fluctuations following a Gaussian distribution with standard deviation $\sigma=2 \mathrm{~m} \mathrm{~s}^{-1}$ to the raw data and then recalculated $\eta$. This procedure was repeated 100 times and the minimum and maximum values for $\eta$ are marked by the errorbars. In this sense the errorbars span the range of values possibly obtained by the analysis when varying the raw data within its uncertainty. 

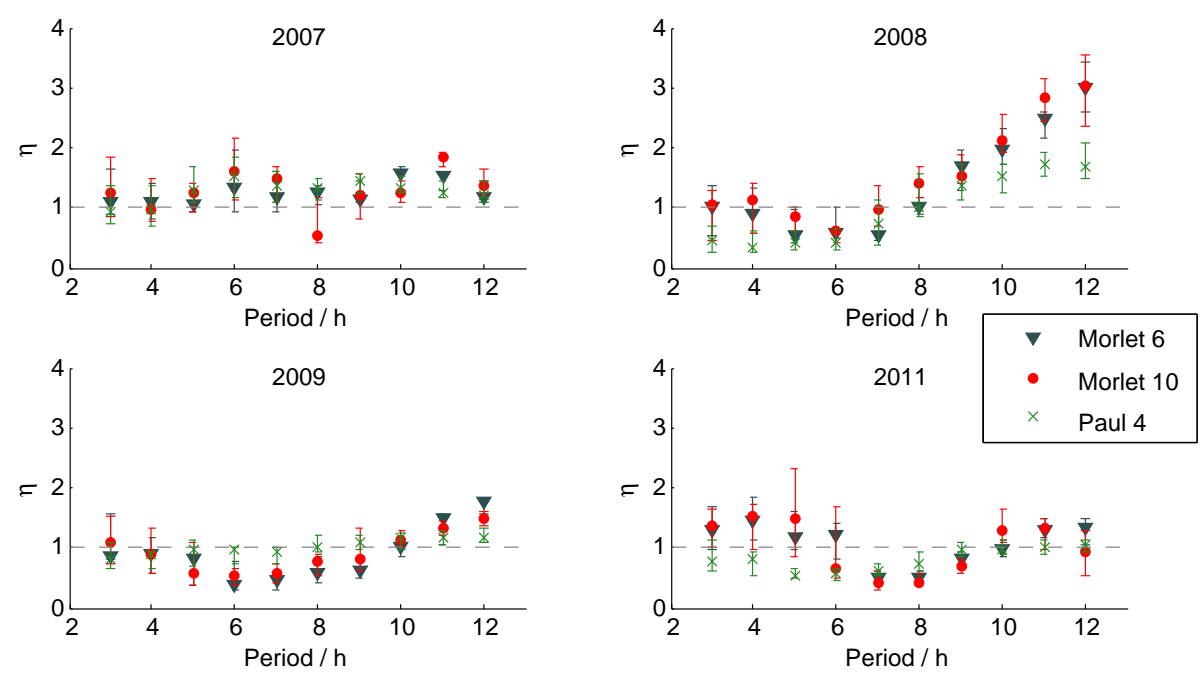

Fig. 5. Ratio $\eta$ (see Eq. 3) for the years 2007, 2008, 2009 and 2011 and three different mother wavelet functions (Morlet with parameter $\omega_{0}=6$ and $\omega_{0}=10$ and Paul of order $\left.m=4\right)$. The errorbars result from variation of the raw data within its uncertainty.

For the years 2007, 2009 and 2011 the ratio $\eta$ exhibits a behaviour which does not indicate any gravity wave influence at neither higher nor lower wave periods. A ratio of $\eta$ equal to 1 (or at least very close to 1 ) is included within the errorbars of all periods of all three years. An exception is $\eta$ for the $7 \mathrm{~h}$ and $8 \mathrm{~h}$ wave in 2011. This could possibly be the influence of the terdiurnal tide, although this effect is not consistently found in the data of the other years. In addition to the terdiurnal tide, the semidiurnal tide could also have an impact on the period dependency of $\eta$. However, we do not find a clear increase or decrease of $\eta$ for wave activity with periods around $12 \mathrm{~h}$. A different situation appears in 2008, where $\eta$ features a clear increasing trend for all three mother wavelet functions in the period range from $6 \mathrm{~h}$ to $12 \mathrm{~h}$ and values distinctly different from $\eta=1$ at periods larger than $9 \mathrm{~h}$. This trend is consistent with model prediction of NLC enhancement due to long period gravity waves and is supported by the scatter plots for the year 2008 in Fig. 6: the brightest NLC occur during comparatively high gravity wave activity in the long period range $(8 \mathrm{~h}$ and $11 \mathrm{~h})$, whereas in the short period range $(3 \mathrm{~h})$ the brightest NLC occur during weak gravity wave activity. It is important to note, that the NLC distribution does not simply follow the gravity wave distribution as in Figs. 2 and 3 and that the accumulation of NLC events at the kinetic energy density of $50 \mathrm{~m}^{2} \mathrm{~s}^{-2}$ in the right panel cannot be explained by an increased occurrence of gravity waves in this energy range.

As the behaviour of $\eta$ in 2008 differs considerably from the other years, we analysed several parameters that could indicate whether the background conditions in 2008 were different. The mean temperatures deduced from satellite data (temperature measurements of the Sounding of the Atmosphere using Broadband Emission Radiometry (SABER) instrument on the Thermosphere Ionosphere Mesosphere Ener- getics Dynamics (TIMED) satellite and the Microwave Limb Sounder (MLS) on the EOS Aura satellite) was neither significantly higher nor lower in 2008 than in the other years. As PMSE (polar mesospheric summer echoes, see Rapp and Lübken, 2004 for a review) are closely related to the existence of ice particles in the mesopause region, the mean PMSE occurrence rates could also hint at special background conditions. Nonetheless, the mean PMSE occurrence rate at ALOMAR in 2008 was not exceptional in any sense (Latteck and Bremer, 2013). The wind spectra and total wind variances do not show any peculiarities as well. However, further analysis of the data of 2008 reveals that the period dependency of $\eta$ significantly depends on only two NLC events. One of these events occurred on 5 August 2008 and is shown in greater detail in Fig. 7. It gives an overview over NLC height and brightness and the normalized kinetic energy in the different period ranges. The NLC event marked by the box is accompanied by enhanced activity of gravity waves with periods longer than $8 \mathrm{~h}$ and greatly reduced activity of the $3 \mathrm{~h}$ and $4 \mathrm{~h}$ wave. Further details on the remarkable wave event as observed from ground and space can be found in Baumgarten et al. (2012).

If the two events are removed from the dataset, i.e. only $12 \mathrm{~h}$ out of $378 \mathrm{~h}$ of lidar measurements in 2008, $\eta$ still features an increase with increasing period, but less substantial and only over a reduced period range as shown in Fig. 8 (compare to upper right panel in Fig. 5). Considering the small amount of data points removed from the dataset, this change is remarkable and indicates that the analysis is highly influenced by the sampling of the data. Drawing general conclusions about a robust correlation between enhanced long period gravity waves and NLC occurrence based on single year data is therefore not possible. 


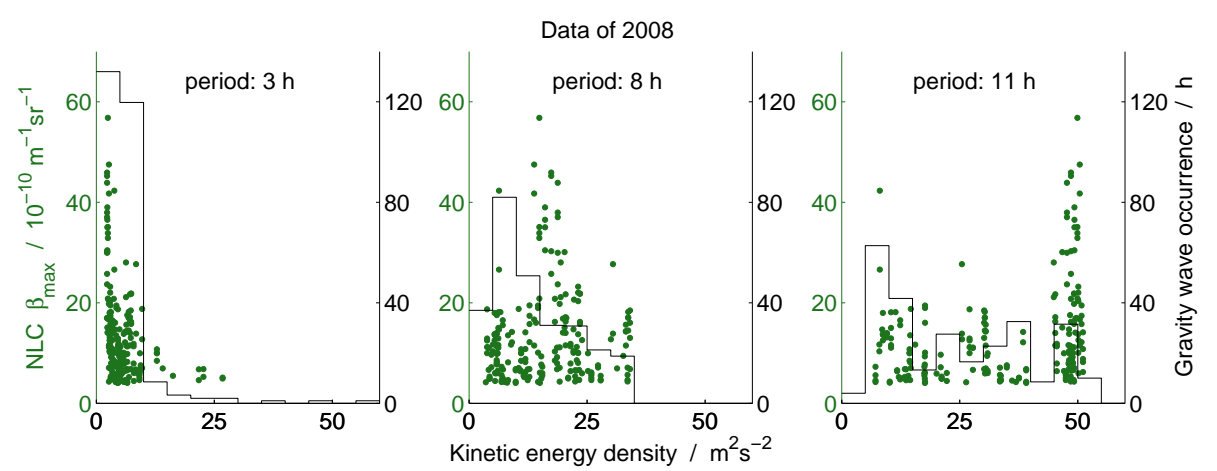

Fig. 6. NLC brightness vs. kinetic energy density for data of 2008 and three different periods ( $3 \mathrm{~h}, 8 \mathrm{~h}, 11 \mathrm{~h})$. The step plot shows the histogram of gravity wave occurrence as in Fig. 2c.

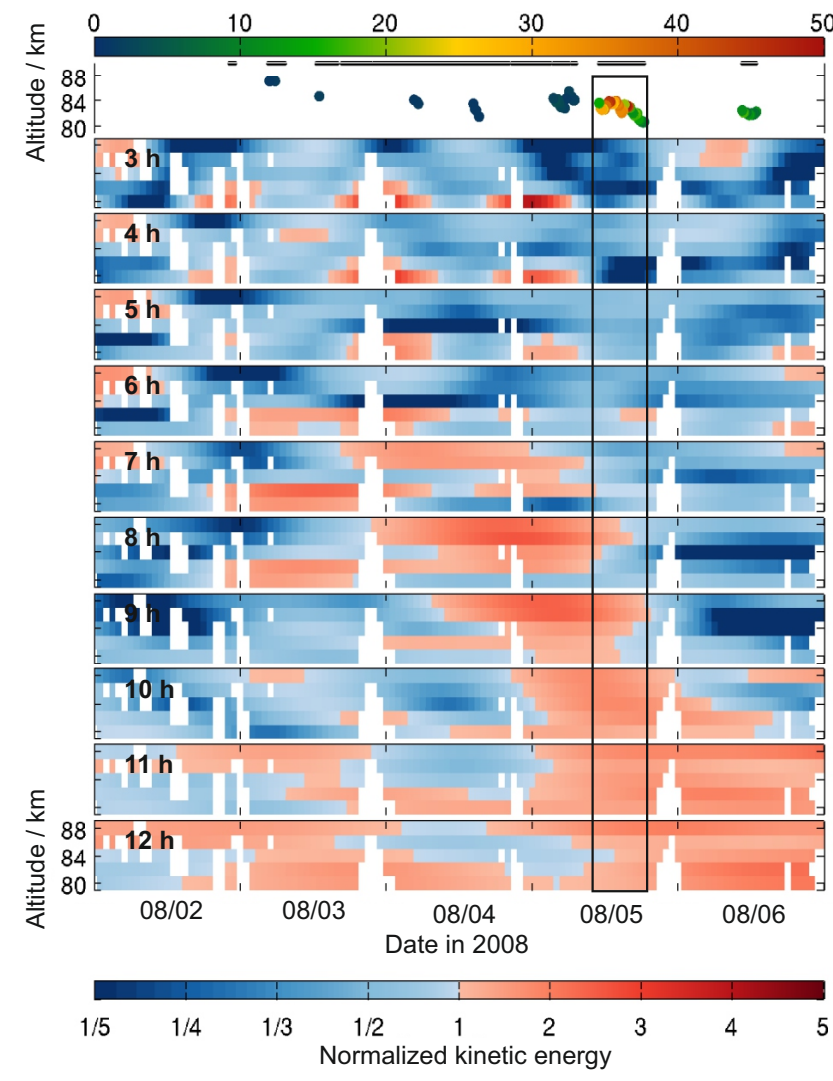

Fig. 7. NLC and gravity wave data for an exceptionally bright NLC on 5 August 2008. The top panel shows the NLC height and colourcoded the maximum backscatter coefficient $\beta_{\max }$. Times of lidar measurement are indicated by the black line above the NLC data. The panels below show the height-time cross-section of normalized kinetic energy for periods between $3 \mathrm{~h}$ and $12 \mathrm{~h}$.

In order to increase the statistical robustness we extended the analysis to the time period from 1999 to 2011 and recalculated $\eta$ for the combined dataset. The result is represented in Fig. 9a, where $\eta$ exhibits values close to 1 with deviations of smaller magnitude than in the single year data

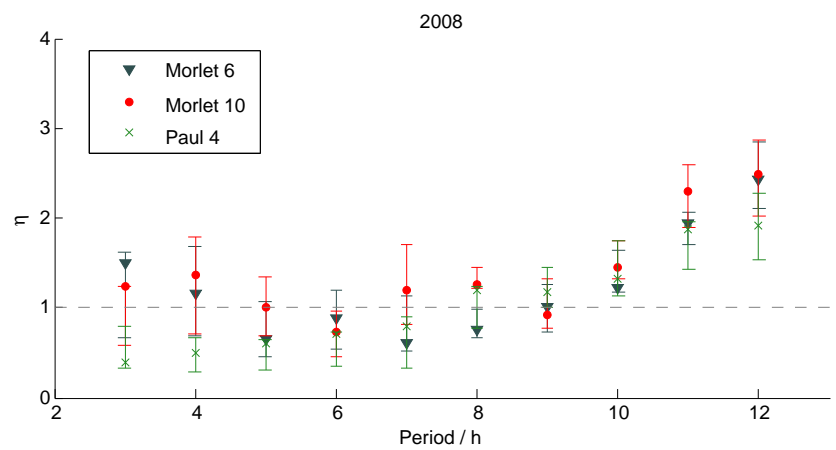

Fig. 8. Same as Fig. 5 for 2008, but with $12 \mathrm{~h}$ of lidar data removed from the dataset.

(compare to Fig. 5). As Chandran et al. (2012) suggest that the brightest PMC are driven by long period gravity waves, panel b of Fig. 9 shows $\eta$ for only strong NLC $\left(\beta_{\max }>13 \times\right.$ $\left.10^{-10} \mathrm{~m}^{-1} \mathrm{sr}^{-1}\right)$. The period dependency of $\eta$ is comparable to the results shown in Fig. 9a with a slightly larger decrease for periods around $7 \mathrm{~h}$. Just as for NLC in the long-term limit $\left(\beta_{\max }>4 \times 10^{-10} \mathrm{~m}^{-1} \mathrm{sr}^{-1}\right)$ we do not find an enhancement of NLC occurrence during strong gravity wave activity in the long period range. As tides possibly bias the gravity wave kinetic energy density, $\eta$ is additionally calculated from the dataset where tides have been removed from the wind and the results are shown in Fig. 9c. Again, the results strongly resemble those presented in Fig. 9a. Note that the decrease at periods around $7 \mathrm{~h}$ is still present, although the terdiurnal tide has been removed. So far, only NLC brighter than the long-term detection limit of $\beta_{\max }=4 \times 10^{-10} \mathrm{~m}^{-1} \mathrm{sr}^{-1}$ were taken into account, but starting from 2006 high sensitivity data with $\beta_{\max }>1 \times 10^{-10} \mathrm{~m}^{-1} \mathrm{sr}^{-1}$ is available. These weak NLC are included in Fig. 9d where $\eta$ is calculated on the basis of the 2006-2011 high sensitivity dataset. The longterm data set in Fig. 9a to c features a small decrease in $\eta$ for periods between $6 \mathrm{~h}$ and $9 \mathrm{~h}$ and is most prominent for strong NLC. This decrease is least pronounced in the Paul wavelet data, as the Paul wavelet has the coarsest period resolution 

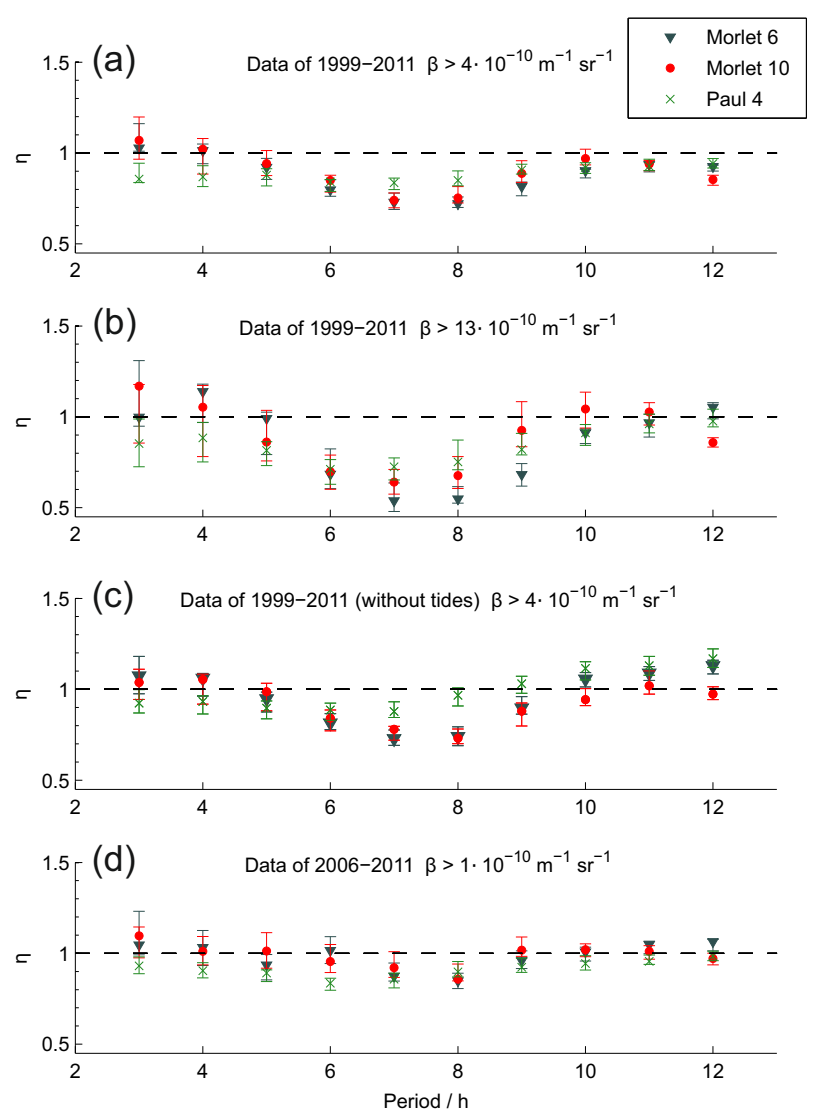

Fig. 9. (a) Ratio $\eta$ as in Fig. 5 for the combined dataset of 19992011 for $\beta_{\max }>4 \times 10^{-10} \mathrm{~m}^{-1} \mathrm{sr}^{-1}$ (long-term detection limit) and (b) for strong NLC with $\beta_{\max }>13 \times 10^{-10} \mathrm{~m}^{-1} \mathrm{sr}^{-1}$. (c) Ratio $\eta$ as in panel a for the combined dataset of 1999-2011 where the tidal components of the wind have been removed. (d) Ratio $\eta$ for the combined dataset of 2006-2011 with NLC detection limit of $\beta_{\max }=1 \times 10^{-10} \mathrm{~m}^{-1} \mathrm{sr}^{-1}$ (high-sensitivity dataset).

and therefore variations of $\eta$ are smoothed out over a larger period range. However, this decrease almost completely vanishes in the high sensitivity data (panel d of Fig. 9), where $\eta=1$ lies within the range of possible values of $\eta$ for all periods except the $8 \mathrm{~h}$ wave. The mean value of $\eta$ determined by the three wavelet types at the $8 \mathrm{~h}$ wave is $\eta=0.87$, which means that the NLC occurrence rate during reduced gravity wave activity was roughly $15 \%$ higher than during enhanced gravity wave activity. Values of $\eta$ as high as 0.94 lie within the possible range and indicate, that if the $8 \mathrm{~h}$ wave has a special influence at all, it is only of minor importance as $\eta$ does not considerably differ from 1.

The overall conclusion of the analysis of $\eta$ is that including all NLC $\eta$ does not vary significantly over the period range from $3 \mathrm{~h}$ to $12 \mathrm{~h}$ and within the uncertainty the NLC occurrence rates during weak and strong gravity wave activity are equal. For strong NLC a slight reduction of $\eta$ is found for periods around $7 \mathrm{~h}$, which is also found in the dataset without tides.

\section{Discussion}

So far, all previous studies on the correlation of NLC and gravity wave activity basically employed the same method by taking stratospheric density perturbations as a proxy for mesospheric gravity wave strength. Our analysis fundamentally differs in three points. Firstly, we derive gravity wave activity from wind instead of density perturbations and secondly the gravity wave activity is determined in the same altitude range as NLC occur. Density perturbations lead to the potential energy of a gravity wave, whereas wind perturbations result in the kinetic energy. According to Geller and Gong (2010) the kinetic energy is proportional to the potential energy, which has recently been confirmed for the mesopause region by Placke et al. (2013). Thus, for a given period it does not make a difference whether the potential or kinetic energy is used to determine the gravity wave strength and our energy scale is proportional to those used in previous studies. Determining gravity wave activity in the mesopause instead of the stratosphere yields the advantage that no variations of the gravity wave field due to filtering processes have to be considered. Nonetheless, as NLC can be advected horizontally (Gerding et al., 2007), the waves detected in a common volume with NLC might not necessarily be the same waves responsible for their formation. The same waves are only detected if the horizontal scale of the waves is large enough, i.e. several hundred kilometres assuming ice particle growth time of a few hours and typical background winds (see also Kiliani et al., 2013). Note however, that this constraint is less important for NLC in their sublimating phase, as the corresponding time scales are significantly smaller (Rapp et al., 2002, Fig. 8).

Another difference to previous studies, attributed to the almost continuously available wind data, is that short period waves as well as long period gravity waves can be identified and for the first time the predicted enhancement of NLC due to long period gravity waves can be studied. Additionally, from the large dataset of gravity wave energies we are able to perform a detailed analysis of their distribution. It is important to address the question how this energy distribution is possibly distorted by reducing the dataset to only those times when lidar measurements were performed. During the NLC season the lidar measurement time covers between $25 \%$ and $7 \%$ of the total time, varying from year to year (Fiedler et al., 2011). To verify that no artificial bias is introduced due to taking only a small subset, the distribution of $E_{\text {kin }}$ during the whole NLC season and during lidar measurements is examined. Figure 10 gives an exemplary overview over the kinetic energy distribution prior to normalization for the $3 \mathrm{~h}$ wave, $6 \mathrm{~h}$ and $9 \mathrm{~h}$ respectively. No fundamental differences can be found between the two datasets, which is supported by a fairly constant ratio between them both. We therefore conclude that the lidar subset is large enough to adequately cover all energy ranges. 


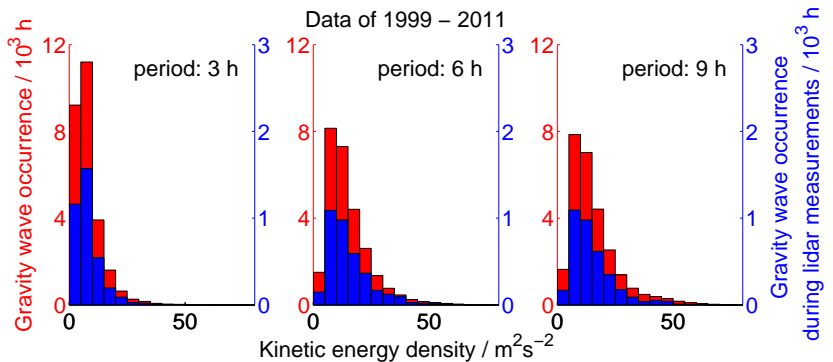

Fig. 10. Gravity wave occurrence of the $3 \mathrm{~h}, 6 \mathrm{~h}$ and $9 \mathrm{~h}$ wave in different energy bins. Red: complete summer season dataset of the years 1999-2011. Blue: dataset limited to times of lidar measurements.

The weak point of our approach is that we are not able to distinguish gravity waves from tides. To study the effect gravity waves alone have on NLC, the tidal component should be removed from the wind data. However, the NLC variation induced by tides should then be removed as well, which would be a rather difficult procedure. We therefore perform our analysis with the wind dataset including the tides and keep in mind, that our results might be modified by tides in the $8 \mathrm{~h}$ and $12 \mathrm{~h}$ wave bands. In addition to tides, planetary waves can also have a significant impact on NLC occurrence (e.g., Merkel et al., 2008; von Savigny et al., 2007). It seems possible that depending on how close the background temperature is to the NLC threshold temperature, gravity waves either have an increased or reduced impact on NLC formation. Background temperature variations due to planetary waves thus induce an additional factor influencing the results of this study and should be addressed in further studies.

The distribution of NLC in Fig. 2a strongly resembles the schematic illustration of Gerrard et al. (2004, Fig. 5) with the pronounced triangular shape in the NLC strength/gravity wave strength plane. Their illustration displayed the theorized relationship between gravity wave activity and NLC brightness for short period gravity waves. At a first sight the resemblance of our data to the illustration could be interpreted as another experimental support of the destructing effect of short period gravity waves on NLC. However, as we have shown, NLC occurrence is independent of gravity wave kinetic energy as indicated by the constant NLC occurrence rates in different energy ranges and for different period bands. The absence of strong NLC during high gravity wave activity in Fig. 2a can simply be explained by the generally rare occurrence of strong NLC. For example, only $1 \%$ of all NLC are brighter than $\beta_{\max }=30 \times 10^{-10} \mathrm{~m}^{-1} \mathrm{sr}^{-1}$ and given only 10 NLC detections at energy densities around $50 \mathrm{~m}^{2} \mathrm{~s}^{-2}$ we would expect less than one to be as bright as $30 \times 10^{-10} \mathrm{~m}^{-1} \mathrm{sr}^{-1}$ in this energy range. While these numbers hold for the $3 \mathrm{~h}$ wave, the arguments can be generalized for larger periods. Thus, concluding from this analysis no enhancement or attenuation of NLC by gravity waves is supported by our data.
The analysis of $\eta$, the ratio of NLC occurrence rates during high and low gravity wave activity, results in the same conclusion. While the data limited to single NLC seasons partly show large deviations from $\eta=1$, the combined dataset of the years 1999-2011 is not indicative of any destructing or enhancing characteristic of gravity waves. Nevertheless, the analysis of the single year data of 2008 revealed two interesting NLC events which were accompanied by enhanced long period gravity wave activity (Fig. 7 shows one of them). The transition period between reduced and enhanced gravity wave activity falls into the range of $6 \mathrm{~h}$ to $8 \mathrm{~h}$. This is in good agreement to model studies by Rapp et al. (2002) who found NLC enhancement due to gravity waves with periods of $6.5 \mathrm{~h}$ and more. Furthermore it is worth remarking that this event is preceded by $36 \mathrm{~h}$ of enhanced wave activity with periods around $8 \mathrm{~h}$. As this preceding enhancement is not found in the wind data without tides, we conclude that it is mainly due to activity of the terdiurnal tide. During the following NLC event one of the highest backscatter coefficients $\left(\beta_{\max }=57 \times 10^{-10} \mathrm{~m}^{-1} \mathrm{sr}^{-1}\right)$ of the whole dataset was measured. This exceptionally strong NLC might suggest that the conditions prior to NLC detection have highly favoured ice particle growth. We can only speculate whether the wave activity prior and during NLC detection were one of the factors enabling NLC of this brightness, but it seems possible that there is a physical connection. To entirely answer questions of this type, the history of air parcels with temperature and humidity in the mesopause region would be needed.

Not finding any correlation of gravity wave activity and NLC occurrence in Andenes agrees with the results of Schöch (2007). One of his explanations for the absence of an anticorrelation refers to a strong thermal tidal influence on NLC occurrence over ALOMAR which is reflected by the semi-diurnal variation of NLC height and brightness. This is confirmed by Fiedler et al. (2011) who found an almost perfect anticorrelation of the diurnal variation of NLC occurrence rates and model mesopause temperatures during times of lidar measurements. In the early morning hours, the cold phase of the tide, NLC occurrence rates as high as $40 \%$ are reached, whereas in the afternoon and evening NLC occurrence rates are less than $20 \%$. Temperature variations, which are one of the main factors controlling NLC properties (e.g., Rapp and Thomas, 2006) can be induced by gravity waves as well as thermal tides, so that in general a superposition of both exist in the mesopause region. In the context of previous studies we conclude that at ALOMAR gravity waves play only a minor role in controlling NLC occurrence compared to the tidal influence. For this reason we do not find any relation of NLC occurrence to gravity wave kinetic energy. Note that we do not find a positive correlation with wave activity in the $11 \mathrm{~h}$ to $13 \mathrm{~h}$ period range because we relate NLC occurrence to the overall strength of a wave and not to a certain phase (like the cold phase) of a wave. Of course we need to stress that our results are only valid for the location of ALOMAR and cannot be generalized. 
Gravity wave strength might vary considerably between different locations. Chandran et al. (2010) have derived gravity wave occurrence rates from polar mesospheric clouds which feature a strong longitudinal variability. They find a longitudinal correlation between gravity wave occurrence and temperature and also an anticorrelation between PMC occurrence and gravity wave activity, possibly because both short and long period gravity waves ultimately lead to reduced PMC brightness (Chandran et al., 2012). ALOMAR is situated in one of the minima of gravity wave occurrence rates whereas Rothera and Sondrestrom are located at a maximum. From this point of view the presence or absence of an anticorrelation of NLC brightness and gravity wave activity can likely be explained by the different levels of gravity wave activity.

\section{Summary}

We combined the 1999-2011 ALOMAR-RMR lidar dataset with wind measurements by MF radar to study the relationship of NLC occurrence and gravity wave activity. Gravity wave kinetic energy in different period bands, derived from the horizontal wind data by means of a wavelet transformation, was obtained in the same volume as NLC were detected. The direct comparison of NLC brightness and gravity wave kinetic energy showed no correlation of these two parameters. After normalization to the occurrence of gravity waves themselves, we found that NLC occurred equally frequently in all energy ranges of all periods. This implies, that the occurrence of NLC is independent of the simultaneously determined gravity wave kinetic energy. In a second approach we divided the gravity wave energy data into two subsets, one of reduced and one of enhanced energy as compared to a $13 \mathrm{yr}$ summer season mean condition. For each subset the NLC occurrence rate was determined. We analysed whether NLC occurred more frequently during enhanced gravity wave activity by looking at the ratio $\eta$ of the NLC occurrence rate during strong and weak gravity wave activity. For the period range of $3 \mathrm{~h}$ to $12 \mathrm{~h}$ this ratio was calculated for the years 2007, 2008, 2009 and 2011 separately and for combined datasets of 1999-2011 and 2006-2011. For the single year data (except 2008) $\eta$ exhibited values in the order of 1 , which means that NLC occurred equally frequently during high and low gravity wave activity, but with quite large fluctuations from one period to the next as well as quite large differences between the three applied mother wavelet functions. The data of 2008 showed a remarkably clear increase of $\eta$ with increasing period, which is the expected trend from microphysical model results (e.g., Rapp et al., 2002). However, it appeared that the increasing trend of $\eta$ was mainly due to two NLC events of $12 \mathrm{~h}$ duration. One of the events was accompanied by enhanced gravity wave activity in periods larger than $8 \mathrm{~h}$ and preceded by $36 \mathrm{~h}$ of enhanced activity in the $7 \mathrm{~h}$ to $9 \mathrm{~h}$ period band, presumably caused by the terdiurnal tide. As this NLC was one of the brightest NLC of the whole dataset, it seems possible that gravity waves have positively influenced the growth of ice particles during this specific NLC. For the combined dataset of the years 1999-2011 $\eta$ shows a slight decrease in the period range from $6 \mathrm{~h}$ to $9 \mathrm{~h}$, which cannot be attributed to the terdiurnal tide. This decrease however vanishes when using the highsensitivity dataset available since 2006 with a detection limit of $\beta_{\text {thres }}=1 \times 10^{-10} \mathrm{~m}^{-1} \mathrm{sr}^{-1}$ and $\eta$ attains values close to 1 for all periods.

From both analysing methods we come to the conclusion that gravity waves above ALOMAR neither negatively nor positively influence NLC occurrence rates. Our findings are in accordance to earlier studies by Schöch (2007). They also agree with the interpretation of the diurnal variation of NLC occurrence rates by Fiedler et al. (2011) who conclude that tidal temperature variations are the primary driver for diurnal NLC occurrence variability. In future, the relative importance of gravity waves and tides influencing NLC parameters should be analysed in dependence of their geographic position.

The service charges for this open access publication have been covered by a Research Centre of the Helmholtz Association.

Edited by: W. Ward

\section{References}

Backhouse, T. W.: The luminous cirrus cloud of June and July, Meteorol. Mag., 20, 133-133, 1885.

Baumgarten, G., Chandran, A., Fiedler, J., Hoffmann, P., Kaifler, N., Lumpe, J., Merkel, A., Randall, C. E., Rusch, D., and Thomas, G.: On the horizontal and temporal structure of noctilucent clouds as observed by satellite and lidar at ALOMAR (69N), Geophys. Res. Lett., 39, L01803, doi:10.1029/2011GL049935, 2012.

Briggs, B. H.: The analysis of spaced sensor records by correlation techniques, in: Middle Atmosphere Program Handbook, edited by: Vincent, R., Vol. 13, 168-188, SCOSTEP, 1984.

Chandran, A., Rusch, D. W., Palo, S. E., Thomas, G. E., and Taylor, M. J.: Gravity wave observations in the summertime polar mesosphere from Cloud Imaging and Particle Size (CIPS) experiment on the AIM spacecraft, J. Atmos. Sol. Terr.-Phy., 71, 392-400, doi:10.1016/j.jastp.2008.09.041, 2009.

Chandran, A., Rusch, D. W., Merkel, A. W., Palo, S. E., Thomas, G. E., Taylor, M. J., Bailey, S. M., and Russell III, J. M.: Polar mesospheric cloud structures observed from the cloud imaging and particle size experiment on the Aeronomy of Ice in the Mesosphere spacecraft: Atmospheric gravity waves as drivers for longitudinal variability in polar mesospheric cloud occurrence, J. Geophys. Res., 115, D13102, doi:10.1029/2009JD013185, 2010.

Chandran, A., Rusch, W., Thomas, G. E., Palo, S. E., Baumgarten, G., Jensen, E. J., and Merkel, A. W.: Atmospheric gravity wave 
effects on polar mesospheric clouds: A comparison of numerical simulations from CARMA 2D with AIM observations, J. Geophys. Res., 117, D20104, doi:10.1029/2012JD017794, 2012.

Chu, X., Gardener, C. S., and Papen, G.: Lidar Observations of Polar Mesospheric Clouds at South Pole: Diurnal Variations, Geophys. Res. Lett., 28, 1937-1940, doi:10.1029/2000GL012524, 2001.

Chu, X., Espy, P., Nott, G. J., Dietrich, J. C., and Gardner, C. S.: Polar mesospheric clouds observed by an iron Boltzmann lidar at Rothera $\left(67.5^{\circ} \mathrm{S}, 68.0^{\circ} \mathrm{W}\right)$, Antarctica from 2002 to 2005 : Properties and implications, J. Geophys. Res., 111, D20213, doi:10.1029/2006JD007086, 2006.

Chu, X., Yamashita, C., Espy, P. J., Nott, G. J., Jensen, E. J., Liu, H.L., Huang, W., and Thayer, J. P.: Responses of polar mesospheric cloud brightness to stratospheric gravity waves at the South Pole and Rothera, Antarctica, J. Atmos. Sol.-Terr. Phy., 71, 434-445, doi:10.1016/j.jastp.2008.10.002, 2009.

Dalin, P., Pertsev, N., Zadorozhny, A., Connors, M., Schofield, I., Shelton, I., Zalcik, M., T.McEwan, McEachran, I., Frandsen, S., Hansen, O., Andersen, H., Sukhodoev, V., Perminov, V., and Romejko, V.: Ground-based observations of noctilucent clouds with a northern hemisphere network of automatic digital cameras, J. Atmos. Sol.-Terr. Phy., 70, 1460-1472, doi:10.1016/j.jastp.2008.04.018, 2008.

DeLand, M. T., Shettle, E. P., Thomas, G. E., and Olivero, J. J.: A quarter-century of satellite polar mesospheric cloud observations, J. Atmos. Sol.-Terr. Phy., 68, 9-29, doi:10.1016/j.jastp.2005.08.003, 2006.

DeLand, M. T., Shettle, E. P., Thomas, G. E., and Olivero, J. J.: Latitude-dependent long-term variations in polar mesospheric clouds from SBUV version 3 PMC data, J. Geophys. Res., 112, D10315, doi:10.1029/2006JD007857, 2007.

Eckermann, S. D.: Effect of background winds on vertical wavenumber spectra of atmospheric gravity waves, J. Geophys. Res., 100, 14097-14112, doi:10.1029/95JD00987, 1995.

Ern, M., Preusse, P., Gille, J. C., Hepplewhite, C. L., Mlynczak, M. G., Russell III, J. M., and Riese, M.: Implications for atmospheric dynamics derived from global observations of gravity wave momentum flux in stratosphere and mesosphere, J. Geophys. Res., 116, D19107, doi:10.1029/2011JD015821, 2011.

Farge, M.: Wavelet transforms and their applications to turbulence, Annu. Rev. Fluid Mech., 24, 395-457, doi:10.1146/annurev.fluid.24.1.395, 1992.

Fiedler, J., Baumgarten, G., and von Cossart, G.: Mean diurnal variations of noctilucent clouds during 7 years of lidar observations at ALOMAR, Ann. Geophys., 23, 1175-1181, doi:10.5194/angeo-23-1175-2005, 2005.

Fiedler, J., Baumgarten, G., and Lübken, F.-J.: NLC observations during one solar cycle above ALOMAR, J. Atmos. Sol.-Terr. Phy., 71, 424-433, doi:10.1016/j.jastp.2008.11.010, 2009.

Fiedler, J., Baumgarten, G., Berger, U., Hoffmann, P., Kaifler, N., and Lübken, F.-J.: NLC and the background atmosphere above ALOMAR, Atmos. Chem. Phys., 11, 5701-5717, doi:10.5194/acp-11-5701-2011, 2011.

Gadsden, M. and Schröder, W.: Noctilucent Clouds, SpringerVerlag, 1989.

Geller, M. A. and Gong, J.: Gravity wave kinetic, potential, and vertical fluctuation energies as indicators of different frequency gravity waves, J. Geophys. Res., 115, D11111, doi:10.1029/2009JD012266, 2010.
Gerding, M., Höffner, J., and Rauthe, M.: Simultaneous observations of temperatures and ice-particles in the midlatitude mesopause region, Adv. Space Res., 40, 785-793, doi:10.1016/j.asr.2007.01.020, 2007.

Gerrard, A. J., Kane, T. J., Thayer, J. P., and Eckermann, S. D.: Concerning the upper stratospheric gravity wave and mesospheric cloud relationship over Sondrestrom, Greenland, J. Atmos. Sol.Terr. Phy., 66, 229-240, doi:10.1016/j.jastp.2003.12.005, 2004.

Gonzalez, N., Hauchecorne, A., Kirkwood, S., Lübken, F.-J., Manson, A. H., Mourier, A., Schmidlin, F. J., Schminder, R., Kürschner, D., Singer, W., and Widdel, H.-U.: Intercomparisons of simultaneous remote and in situ wind measurements, J. Atmos. Terr. Phys., 56, 1985-2001, doi:10.1016/00219169(94)90024-8, 1994.

Hoffmann, P., Becker, E., Singer, W., and Placke, M.: Seasonal variation of mesospheric waves at northern middle and high latitudes, J. Atmos. Sol.-Terr. Phy., 72, 1068-1079, doi:10.1016/j.jastp.2010.07.002, 2010.

Holton, J. R.: The Role of Gravity Wave Induced Drag and Diffusion in the Momentum Budget of the Mesosphere, J. Atmos. Sci., 39, 791-799, 1982.

Innis, J. L., Klekociuk, A. R., Morris, R. J., Cunningham, A. P., Graham, A. D., and Murphy, D. J.: A study of the relationship between stratospheric gravity waves and polar mesospheric clouds at Davis Antarctica, J. Geophys. Res., 113, D14102, doi:10.1029/2007JD009031, 2008.

Jensen, E. J. and Thomas, G. E.: Numerical simulations of the effects of gravity waves on noctilucent clouds, J. Geophys. Res., 99, 3421-3430, doi:10.1029/93JD01736, 1994.

Jesse, O.: Auffallende Abenderscheinung am Himmel, Meteor. Z., 2, 311-312, 1885.

Kaifler, N., Baumgarten, G., Fiedler, J., and Lübken, F.-J.: Quantification of waves in lidar observations of noctilucent clouds at scales from seconds to minutes, Atmos. Chem. Phys. Discuss., 13, 7397-7429, doi:10.5194/acpd-13-7397-2013, 2013.

Kiliani, J., Baumgarten, G., Lübken, F.-J., Berger, U., and Hoffmann, P.: Temporal and spatial characteristics of the formation of strong noctilucent clouds, J. Atmos. Sol.-Terr. Phy., 104, 151166, doi:10.1016/j.jastp.2013.01.005, 2013.

Latteck, R. and Bremer, J.: Long-term changes of polar mesospheric summer echoes at $69^{\circ} \mathrm{N}$, J. Geophys. Res., 118, 10441-10448, doi:10.1002/jgrd.50787, 2013.

Leslie, R. C.: Sky glows, Nature, 16, 245-245, 1885.

Liu, Y., Liang, X. S., and Weisberg, R. H.: Rectification of the Bias in the Wavelet Power Spectrum, J. Atmos. Ocean. Tech., 24, 2093-2102, doi:10.1175/2007JTECHO511.1, 2007.

Lübken, F.-J. and Berger, U.: Latitudinal and interhemispheric variation of stratospheric effects on mesospheric ice layer trends, J. Geophys. Res., 116, D00P03, doi:10.1029/2010JD015258, 2011.

Lübken, F.-J., Berger, U., and Baumgarten, G.: Stratospheric and solar cycle effects on long-term variability of mesospheric ice clouds, J. Geophys. Res., 114, D00I06, doi:10.1029/2009JD012377, 2009.

Merkel, A. W., Garcia, R. R., Bailey, S. M., and Russell III, J. M.: Observational studies of planetary waves in PMCs and mesospheric temperature measured by SNOE and SABER, J. Geophys. Res., 113, D14202, doi:10.1029/2007JD009396, 2008.

Merkel, A. W., Rusch, D. W., Palo, S. E., Russel III, J. M., and Bailey, S. M.: Mesospheric planetary wave effects on global PMC 
variability inferred from AIM-CIPS and TIMED-SABER for the northern summer 2007 PMC season, J. Atmos. Sol.-Terr. Phy., 71, 381-391, doi:10.1016/j.jastp.2008.12.001, 2009.

Pautet, P.-D., Stegman, J., Wrasse, C. M., Nielsen, K., Takahashi, H., Taylor, M. J., Hoppel, K. W., and Eckermann, S. D.: Analysis of gravity waves structures visible in noctilucent cloud images, J. Atmos. Sol.-Terr. Phy., 73, 2082-2090, doi:10.1016/j.jastp.2010.06.001, 2011.

Placke, M., Hoffmann, P., Gerding, M., Becker, E., and Rapp, M.: Testing linear gravity wave theory with simultaneous wind and temperature data from the mesosphere, J. Atmos. Sol.-Terr. Phy., 93, 57-69, doi:10.1016/j.jastp.2012.11.012, 2013.

Preusse, P., Eckermann, S. D., Ern, M., Oberheide, J., Picard, R. H., Roble, R. G., Riese, M., Russell III, J. M., and Mlynczak, M. G.: Global ray tracing simulations of SABER gravity wave climatology, J. Geophys. Res., 114, D08126, doi:10.1029/2008JD011214, 2009.

Rapp, M. and Lübken, F.-J.: Polar mesosphere summer echoes (PMSE): Review of observations and current understanding, Atmos. Chem. Phys., 4, 2601-2633, doi:10.5194/acp-4-2601-2004, 2004.

Rapp, M. and Thomas, G. E.: Modeling the microphysics of mesospheric ice particles: Assessment of current capabilities and basic sensitivities, J. Atmos. Sol.-Terr. Phy., 68, 715-744, doi:10.1016/j.jastp.2005.10.015, 2006.

Rapp, M., Lübken, F.-J., Müllemann, A., Thomas, G. E., and Jensen, E. J.: Small-scale temperature variations in the vicinity of NLC: Experimental and model results, J. Geophys. Res., 107, 4392, doi:10.1029/2001JD001241, 2002.

Sato, K., Watanabe, S., Kawatani, Y., Tomikawa, Y., Miyazaki, K., and Takahashi, M.: On the origins of mesospheric gravity waves, Geophys. Res. Lett., 36, L19801, doi:10.1029/2009GL039908, 2009.

Schöch, A.: Thermal structure and gravity waves in the Arctic middle atmosphere above ALOMAR $\left(69.3^{\circ} \mathrm{N}, 16.0^{\circ} \mathrm{E}\right)$, Ph.D. thesis, Leibniz-Institut für Atmosphärenphysik, Universität Rostock, Kühlungsborn, Germany, 151 pp., available at: http: //www.iap-kborn.de/fileadmin/user_upload/MAIN-abteilung/ optik/Forschung/Doktorarbeiten/schoech_diss.pdf (last access: 1 June 2013), 2007.
Shettle, E. P., DeLand, M. T., Thomas, G. E., and Olivero, J. J.: Long term variations in the frequency of polar mesospheric clouds in the Northern Hemisphere from SBUV, Geophys. Res. Lett., 36, L02803, doi:10.1029/2008GL036048, 2009.

Singer, W., Keuer, D., and Eriksen, W.: The Alomar MF Radar: Technical design and first results, in: Proceedings of the 13th ESA Symposium on European Rocket and Balloon Programmes and Related Research, Oeland, Sweden (ESA SP-397), edited by: Kaldeich-Schürmann, B., 101-103, 1997.

Thayer, J. P., Rapp, M., Gerrard, A. J., Gudmundsson, E., and Kane, T. J.: Gravity-wave influences on Arctic mesospheric clouds as determined by a Rayleigh lidar at Sondrestrom, Greenland, J. Geophys. Res., 108, 8449, doi:10.1029/2002JD002363, 2003.

Torrence, C. and Compo, G. P.: A Practical Guide to Wavelet Analysis, B. Am. Meteorol. Soc., 79, 61-78, doi:10.1175/15200477(1998)079<0061:APGTWA>2.0.CO;2, 1998.

Turco, R. P., Toon, O. B., Whitten, R. C., Keesee, R. G., and Hollenbach, D.: Noctilucent clouds: Simulations studies of their genesis, properties and global influences, Planet. Space Sci., 30, 1147-1181, doi:10.1016/0032-0633(82)90126-X, 1982.

von Savigny, C., Robert, C., Bovensmann, H., Burrows, J. P., and Schwartz, M.: Satellite observations of the quasi 5-day wave in noctilucent clouds and mesopause temperatures, Geophys. Res. Lett., 34, L24808, doi:10.1029/2007GL030987, 2007.

von Zahn, U., von Cossart, G., and Fiedler, J.: Tidal variations of noctilucent clouds measured at $69^{\circ} \mathrm{N}$ latitude by groundbased lidar, Geophys. Res. Lett., 25, 1289-1292, doi:10.1029/98GL00546, 1998.

von Zahn, U., von Cossart, G., Fiedler, J., Fricke, K. H., Nelke, G., Baumgarten, G., Rees, D., Hauchecorne, A., and Adolfsen, K.: The ALOMAR Rayleigh/Mie/Raman lidar: objectives, configuration, and performance, Ann. Geophys., 18, 815-833, doi:10.1007/s00585-000-0815-2, 2000.

Witt, G.: Height, structure and displacements of noctilucent clouds, Tellus A, 14, 1-18, doi:10.1111/j.2153-3490.1962.tb00115.x, 1962. 